Bull. Mater. Sci., Vol. 13, No. 5, December 1990, pp. 351-364. (C) Printed in India.

\title{
Metallurgical characteristics of electroslag-refined MDN 250 maraging steel
}

\author{
K R UDUPA, D H SASTRY* and G N K IYENGAR* \\ Department of Metallurgical Engineering, Karnataka Regional Engineering College, \\ Srinivasnagar, Surathkal 574 157, India \\ *Department of Metallurgy, Indian Institute of Science, Bangalore 560012, India
}

MS received 13 March 1990; revised 15 October 1990

\begin{abstract}
MDN-250 maraging steel was electroslag-refined in a $350 \mathrm{kVA}$ DC ESR unit using a slag of composition, $\mathrm{CaF}_{2}-65, \mathrm{CaO}-9, \mathrm{Al}_{2} \mathrm{O}_{3}-2 \mathrm{O}, \mathrm{TiO}_{2}-5$, and $\mathrm{MoO}_{3}-1$ (wt \% basis) in straight as well as reverse polarity modes of melting. The chemical homogeneity of the ingots was established by $\mathrm{X}$-ray fluorescence, plasma scan and spectrovac methods. The dissolved gas content ( $O$ and $N$ ) in the ingots was determined by a LECO gas analyser. Volume fraction, density and size distribution of inclusions in the ingots and the electrode were determined in a Quantimet image analyser. These results were supplemented by EPMA and SEM studies on selected inclusions. Mechanical properties of the ingots in the heat-treated and aged conditions were assessed and compared with those of the electrode material.

The present results confirm that the reverse polarity mode of melting is best suited for producing quality maraging steels for the ingots produced by this mode of melting were found to possess superior metallurgical characteristics in terms of cleanliness and mechanical properties compared to those produced by the straight polarity ESR route and other conventional methods.
\end{abstract}

Keywords. Electrosiag refining; maraging steel; inclusion content; metallurgical characteristics.

\section{Introduction}

Maraging steels are characterized by two unique properties: ability to form martensite without quenching and to exhibit age-hardening characteristics. These steels have emerged as alternative materials to conventional quenched and tempered steels for such advanced technologies as aerospace, nuclear and gas turbine, to name only a few. The most attractive properties of maraging steels include, (i) excellent combination of strength and toughness, (ii) good weldability, and (iii) minimum distortion during hardening.

Nearly 30 grades of maraging steels including $\mathrm{Ni}-\mathrm{Cr}, \mathrm{Ni}-\mathrm{Co}-\mathrm{Mo}$ and $\mathrm{Ni}-\mathrm{Co}-$ Mo-Cr types have been developed during the past several years. Maraging steels generally contain $<0.03 \mathrm{wt} \%$ carbon. At least $17 \mathrm{wt} \%(\mathrm{Ni}+\mathrm{Cr})$ is required to impart high toughness. Other alloying elements present in maraging steels are Co: 6-7\%, Mo: 4-6\%, Ti: 0.1-1.4\%, Al: $0 \cdot 1-0.3 \%$, Nb: $0 \cdot 1-0.4 \%$, Be: $0 \cdot 1 \%$, Cu: $0 \cdot 1-0.2 \%$, and $\mathrm{W}$ and $\mathrm{V}$ up to $6 \%$ in special cases. These steels are generally produced by the combination of vacuum induction melting (VIM) and vacuum arc remelting (VAR) processes. Preliminary melting of maraging steel is carried out in a vacuum melting furnace in which carefully selected scrap is charged along with the desired alloying elements in the required proportion. The charge is melted and cast in vacuum in the form of electrodes and they are further refined by vacuum arc remelting process. 
Dissolved gases like hydrogen and nitrogen are removed from the metal and microsegregation is considerably reduced.

The role of various alloying elements in developing high strength and toughness in maraging steels is well documented in literature (Perkas 1985; Bannerjee and Hauser 1977; Hertzberg 1978). Among these, Ti content should be carefully controlled because excess $\mathrm{Ti}$ leads to the formation of Ti-based inclusions with an attendant loss of ductility and impact strength. Maraging steels generally contain four types of titanium-based inclusions - nitrides, carbonitrides, carbosulphides and phosphides. Phosphides completely dissolve during heating and hot working. A major portion of other inclusions and carbides are formed due to segregation. Fracture is initiated by cracking of these inclusions. The toughness of maraging steels can be further improved by keeping carbon and nitrogen at low levels (Krasnikov and Kuzmenko 1982).

Maraging steels can be readily hot-worked by any conventional forming process, where the heating is done in an open furnace since there is no risk of decarburization. Hot working is carried out in the temperature range $1125-1375 \mathrm{~K}$ followed by air cooling. A simple ageing treatment in the range $725-775 \mathrm{~K}$ hardens the material to the desired level. The tensile strength of maraging steel lies in the range 1400-2800 MPa and their resistance to brittle fracture is excellent. This depends on the plasticity, toughness and fineness of martensitic matrix structure, morphology of the precipitate $\left(\mathrm{Ni}_{3} \mathrm{Ti}\right)$ and impurity content $(\mathrm{S}, \mathrm{P}, \mathrm{N}, \mathrm{C})$.

Although the melt-cast-forge route via the VIM-VAR process is fairly satisfactory for producing maraging steels for advanced technologies, it may be desirable to produce the materials with minimum inclusion content which is not always assured in the VIM-VAR route. This problem can be successfully overcome by remelting the product obtained by this route through electroslag refining process (ESR) which is known to produce quality steels with consistent chemistry and minimum inclusion content. However, one of the major problems in electroslag-refining of maraging steels is the loss of reactive element like $\mathrm{Ti}$ which is an indispensable alloying element. Some improvement in the level of recovery of $\mathrm{Ti}$ can be achieved if the electrode surface is subjected to stringent cleaning treatment. Further, melting at low oxygen partial pressure favours Ti recovery (Robinson and Graninger 1963). Fontaine and Palmer (1972) found a 55 to $63 \%$ Ti loss when maraging steel was electroslag-refined in a conventional way using a slag of $70 \% \mathrm{CaF}_{2}$ and $30 \% \mathrm{Al}_{2} \mathrm{O}_{3}$. However, the $\mathrm{Ti}$ loss was reduced to $8-17 \%$ when the melting was carried out in argon atmosphere using the same slag. Besides, using a slag of composition $70 \% \mathrm{CaF}_{2}, 20 \% \mathrm{Al}_{2} \mathrm{O}_{3}$ and $10 \% \mathrm{TiO}_{2}$ resulted in high $\mathrm{Ti}$ recovery but had an adverse effect on the inclusion content of the ingot (Fontaine and Palmer 1972). Despite this, the ESR-melted steel possessed properties comparable to those of VAR. The aim of the present work is to examine the effect of some process parameters on the chemistry, inclusion content, microstructure and mechanical properties of maraging steel ingots produced by ESR process and compare them with those produced by VIM-VAR route.

\section{Experimental details}

Maraging steel, grade MDN 250, supplied by M/s Midhani, Hyderabad was used in this study. The composition of the steel was Ni $(17 \cdot 24 \%)$, Mo $(4 \cdot 7 \%)$, Co $(7 \cdot 3 \%), \mathrm{Ti}$ 
Table 1. Melt parameters of ESR process.

\begin{tabular}{ll}
\hline Melting current & $3500-3800 \mathrm{~A}$ \\
Melting voltage & $25-30 \mathrm{~V}$ \\
Electrode diameter & $60 \mathrm{~mm}$ \\
Mould diameter & $100 \mathrm{~mm}$ \\
Fill ratio & $60 \%$ \\
Melt rate & $0 \cdot 75-0 \cdot 85 \mathrm{~kg} / \mathrm{min}$ \\
Wt. of slag & $0 \cdot 16-0 \cdot 18 \mathrm{~kg} / \mathrm{kg}$ of metal melted \\
Atmosphere above the melt & Normal atmosphere \\
Temperature of the slag & $1820-1870 \mathrm{~K}$ \\
\hline
\end{tabular}

$(0 \cdot 32 \%), \mathrm{Al}(0 \cdot 15 \%)$ and $\mathrm{Fe}$ formed the remaining composition. The material was hot-forged from $240 \mathrm{~mm}$ dia to a final diameter of $60 \mathrm{~mm}$ with start and finish temperatures of 1473 and $1073 \mathrm{~K}$ respectively. Electroslag refining was carried out in a $350 \mathrm{kVA}$ DC ESR unit using reverse polarity (electrode positive-ingot no. 7RP3) and straight polarity (electrode negative-ingot no. 8SN3) modes of melting. The slag composition was $\mathrm{CaF}_{2}(65 \%), \mathrm{Al}_{2} \mathrm{O}_{3}(20 \%), \mathrm{CaO}(9 \%), \mathrm{TiO}_{2}(5 \%)$ and $\mathrm{MoO}_{3}$ $(1 \%)$. Other process parameters chosen for ESR melting are summarized in table 1. The slag components were taken in the required proportion and thoroughly mixed and prefused in a DC ESR unit using a graphite electrode. The slag was then powdered and preserved in an oven maintained at $600-700 \mathrm{~K}$. Solid charge starting technique was used for initiating the melting operation. Electrodes were thoroughly cleaned to prevent any entry of oxygen into the melt. At the end of melting, the power supply was gradually reduced in such a manner as to impose a condition of hot topping. ESR-melted maraging steel ingots were then heat-treated by soaking at $1300 \mathrm{~K}$ for $12 \mathrm{~h}$ followed by air-cooling. They were cut into suitable sizes for further machining and then aged at $775 \mathrm{~K}$ for $3.5 \mathrm{~h}$. Preliminary experiments were carried out to establish the optimum ageing conditions. The electrode samples were also given the same ageing treatment to obtain the highest hardness. The major alloying elements in maraging steel like Ni, Co and Mo were analysed by XRF and minor elements like $\mathrm{Ti}$ and $\mathrm{Al}$ by plasma scan analyser. Nitrogen and oxygen present in the sample were analysed by a LECO gas analyser. A Quantimet image analyser was employed to determine the area fraction, density and distribution of inclusions. EPMA was studied on selected inclusions to map the major elements present in them. Microprocessor based Instron hydraulic testing machine was used for tensile and fracture toughness testing. Plane strain fracture toughness was measured on ASTM-399 standard compact tension specimens of $12.5 \mathrm{~mm}$ thickness. Impact testing was carried out at $295 \mathrm{~K}$ in an instrumented impact testing machine. Apart from Charpy energy, various other material properties like dynamic yield strength $\left(\sigma_{y d}\right)$, dynamic fracture toughness $\left(K_{1 d}\right)$ and ductility index were also obtained by employing standard methods (Ireland 1973). Fractographic studies on fractured surfaces were made using JEOL scanning electron and stereo microscopes.

\section{Results and discussion}

ESR ingots were found to be free from surface defects like ripples, porosity, cold shut and hot tear and gross defects like blowholes and slag entrapment. Photomicrographs 

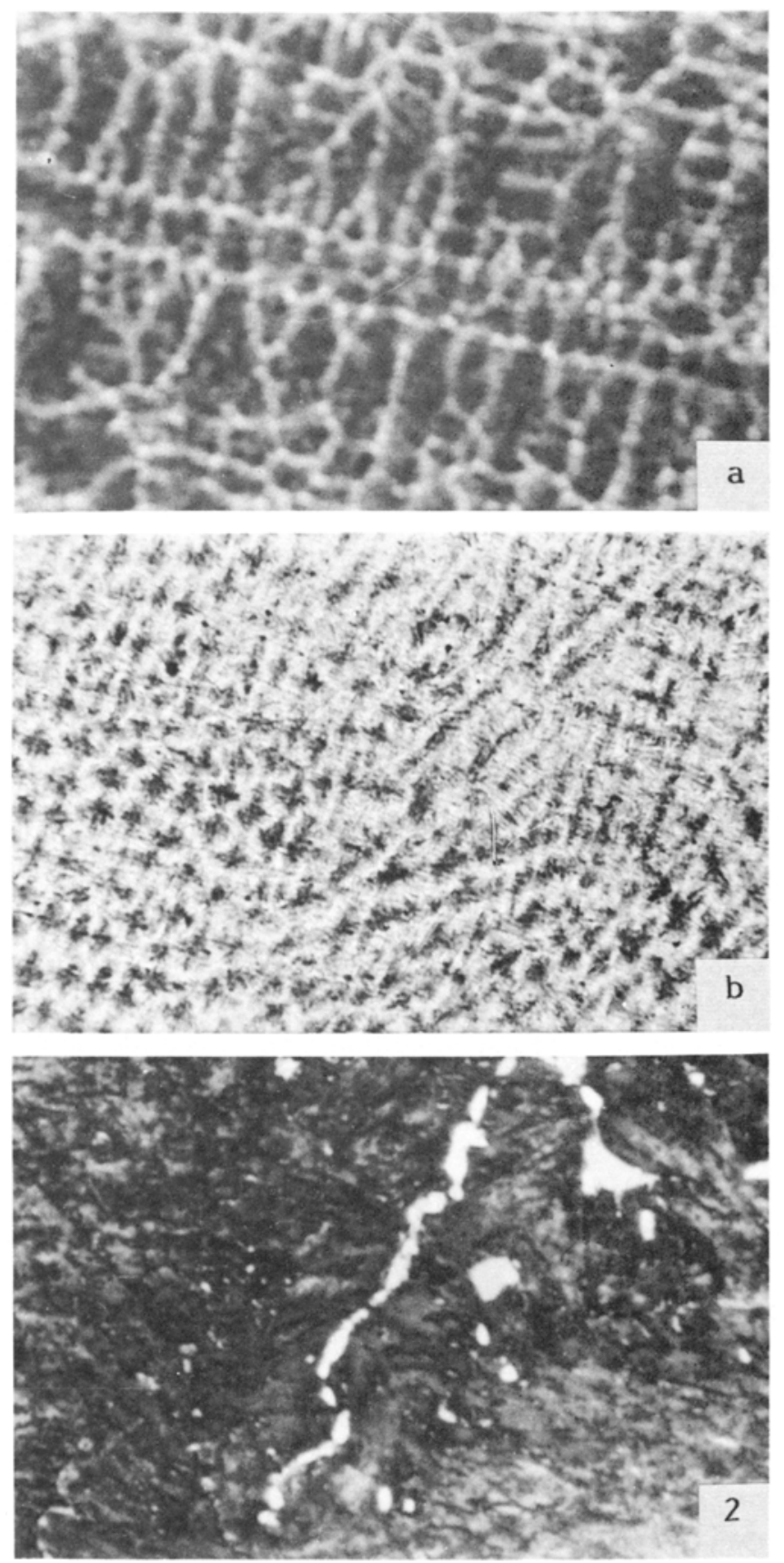

Figures 1 and 2. Photomicrographs $(\times 25)$ of ESR-melted maraging steel, ingot 7 RP3, as-cast. Etchant: Oberhoffer's reagent. (a) at the centre reveals coarse dendritic structure. (b) at the side: fine dendritic structure. 2. Photomicrograph $(\times 800) 8 \mathrm{SN} 3$ ingot (centre) heat treated-homogenised at $1300 \mathrm{~K}$ for $12 \mathrm{~h}$. air-cooled. aged at $775 \mathrm{~K} 3 \mathrm{~h}$; reveals a film of precipitate in the grain boundary region (Etchant: $5^{\circ}{ }_{n} \mathrm{Nital}$ ). 
of ESR melted maraging steel 7RP3 (figure 1) reveal dendritic, nonequilibrium microstructure, typical of as-cast material. Ingots were heat-treated according to the procedure explained earlier. Photomicrographs of ingot 8SN3 in the heat-treated condition (figure 2) reveal grain boundary precipitation which is not observed in the case of ingot 7RP3 treated under similar conditions. Hardness of both ingots is about $R_{c} 43$. Chemical composition of the refined and unrefined maraging steel determined by the methods described earlier is given in table 2 . The reported gas content in steel corresponds to an average of 12-15 determinations. It should however be noted that the values for oxygen refer to total oxygen content in steel i.e. both in the combined and uncombined state. The nitrogen content in electrode as well as in the refined ingot was found to be less than the detectable limit of Leco analyser. This confirms that maraging steel does not pick up nitrogen during electroslag remelting in contrast to high alloy steels containing chromium, as reported by Latash and Medovar (1972) and Holzgruber et al (1969). Oxygen pick-up is observed under straight polarity melting condition. Inclusion analysis was carried out at various positions of the ingot and the relevant results are given in table 3 . Figure 3 shows the photomicrographs of inclusions in the electrode and the refined ingots. The distribution of inclusions with respect to size, both at the side and the centre position of 7RP3 ingot and the electrode is given in figure 4 . The density of inclusions larger than $0.002 \mathrm{~mm}$ measured at two radial positions is presented in table 4 . The results of EPMA studies on the nature of inclusion/precipitates in the maraging steel are presented in table 5. Particles selected for elemental mapping by EPMA (figures 5a and 5b) can be inclusions and/or precipitates; it is not easy to distinguish between them unambiguously because of the difficulty in detecting oxygen by EPMA. However, it is possible to speculate the types of inclusion phases present in a given particle from the information obtained from EPMA results as summarized in table 5. For example, particles containing

Table 2. Chemical composition ( $\mathrm{wt}^{\circ} \%$ ) of ESR-melted and non-ESR melted maraging steel.

\begin{tabular}{lccccccc}
\hline Ingot No. & $\mathrm{Ni}$ & $\mathrm{Mo}$ & $\mathrm{Co}$ & $\mathrm{Ti}$ & $\mathrm{Al}$ & $\mathrm{O}$ & $\mathrm{N}$ \\
\hline Electrode & 17.24 & 4.69 & 7.29 & 0.32 & 0.15 & 0.001 & LDL $^{*}$ \\
7 RP3 & 17.45 & 4.42 & 7.91 & 0.17 & 0.11 & 0.001 & LDL \\
8 SN3 & 17.84 & 4.46 & 8.20 & 0.25 & 0.13 & 0.0045 & LDL \\
\hline
\end{tabular}

${ }^{*}$ less than the detectable limit $(0 \cdot 0001 \mathrm{wt} \%)$

Table 3. Inclusion content of ESR-melted and non-ESR melted maraging steel.

\begin{tabular}{lccc} 
Ingot No. & $\begin{array}{c}\text { Sample } \\
\text { position in } \\
\text { the ingot }\end{array}$ & $\begin{array}{c}\text { Volume } \\
\text { fraction of } \\
\text { inclusions }(\%)\end{array}$ & $\begin{array}{c}\text { Inclusion } \\
\text { density } \\
\left(\mathrm{No} / \mathrm{mm}^{2}\right)\end{array}$ \\
\hline Electrode & & 0.051 & 610 \\
7 RP3 & Side & 0.008 & 260 \\
8SN3 & Centre & 0.020 & 420 \\
& Side & 0.022 & 580 \\
\hline
\end{tabular}



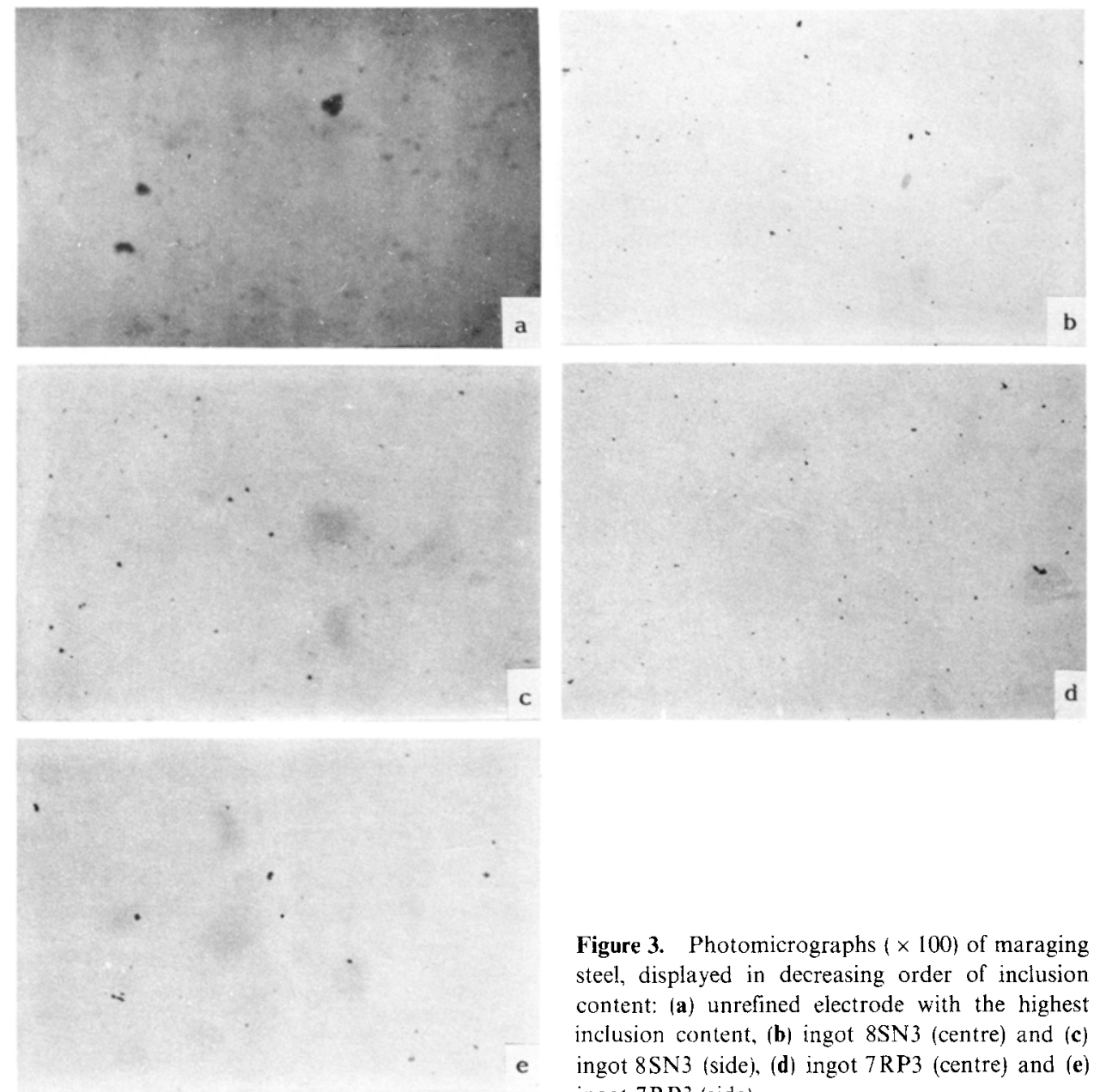

Figure 3. Photomicrographs $(\times 100)$ of maraging steel, displayed in decreasing order of inclusion content: (a) unrefined electrode with the highest inclusion content, (b) ingot $8 \mathrm{SN} 3$ (centre) and (c) ingot 8SN3 (side), (d) ingot 7RP3 (centre) and (e) ingot 7 RP3 (side).

elements such as $\mathrm{Mg}, \mathrm{Ca}$ and $\mathrm{Na}$ are deemed to be oxide inclusions as these elements are not likely to form intermetallic compounds in maraging steels, whereas particles containing elements like Fe, Ti, Al and Ni may form a host of oxides, sulphides or intermetallic compounds. Furthermore, $\mathrm{Al}$ may also be present as $\mathrm{AlN}$ and $\mathrm{Ti}$ as carbonitride or carbosulphide. Table 5 also reveals that the oxides of $\mathrm{Mg}, \mathrm{Ca}$ and $\mathrm{Na}$ present in the electrode and a small amount of sulphide inclusions incidental in the electrode are eliminated during ESR process.

Tensile properties, fracture toughness and impact properties of the refined and unrefined samples are presented in tables 6,7 and 8 respectively. Figures 6 (a to d) and 7 (a to c) represent SEM photographs and stereo photographs of fractured surfaces under tensile and impact load respectively.

It can be inferred from table 3 that the variation in the chemical composition of the ingot with respect to major alloying elements is within the range of specification. However, $\mathrm{Ti}$ and $\mathrm{Al}$ being highly oxidizable are lost to the slag to a certain extent if proper care is not taken to retain them. The loss can be attributed to the following 


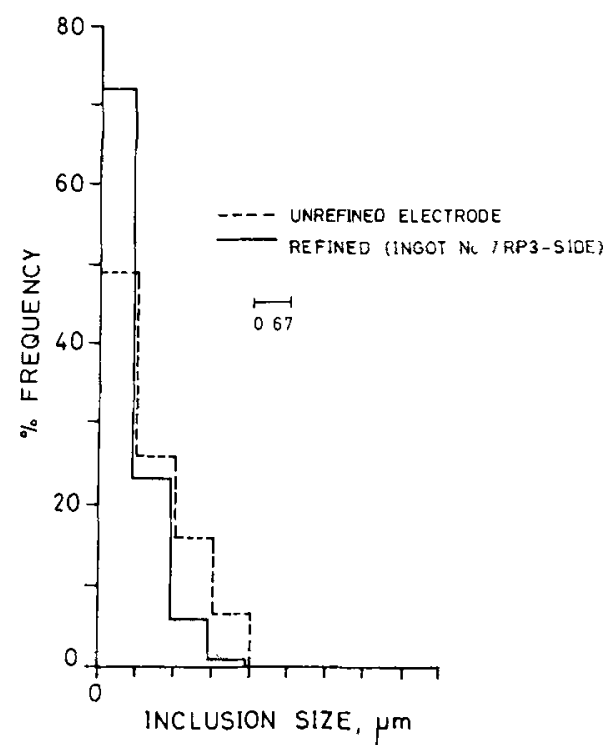

(a)

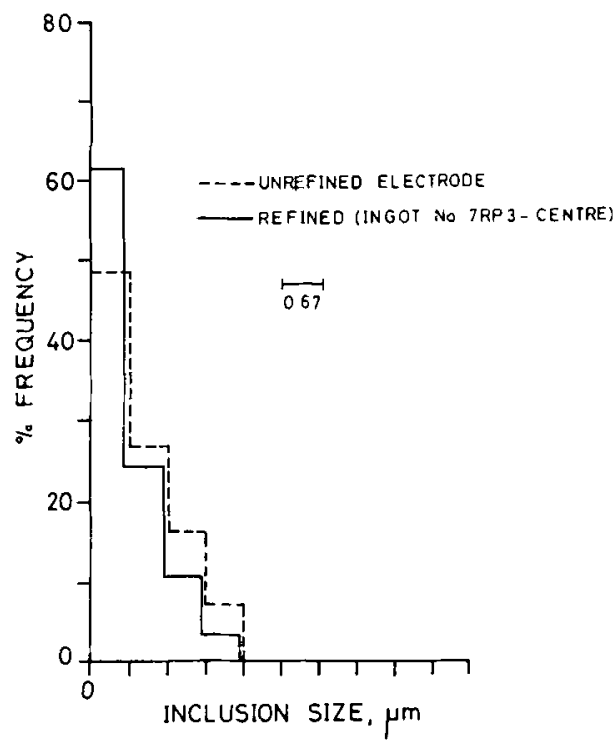

(b)

Figure 4. Histogram showing the size distribution of inclusions in the electrode and ingot 7RP3, (a) at side and (b) at centre.

slag/metal reactions occurring in ESR process:

$$
\begin{aligned}
& {[\mathrm{Ti}]+2[\mathrm{FeO}]=\left[\mathrm{TiO}_{2}\right]+2 \mathrm{Fe},} \\
& 2[\mathrm{Al}]+3[\mathrm{FeO}]=\left[\mathrm{Al}_{2} \mathrm{O}_{3}\right]+3 \mathrm{Fe} .
\end{aligned}
$$

According to the above relations, higher the activity of $\mathrm{TiO}_{2}$ or $\mathrm{Al}_{2} \mathrm{O}_{3}$ in the slag, lower will be the loss of titanium and aluminium for a fixed $\mathrm{FeO}$ activity. The ingots 8SN3 and 7RP3 produced using the same slag composition show some discrepancy with respect to titanium content and also of aluminium albeit to both modes of melting. This discrepancy could be attributed to the electrochemical transport of titanium and aluminium in the form of complex ions arising due to polarity effects. The removal of titanium and aluminium-based inclusions is advantageous from mechanical property considerations. However, this advantage can be easily offset by the simultaneous loss of these elements during ESR melting. This is substantiated by the results presented in tables 3 and 4 on the variation in $\mathrm{Ti}$ and $\mathrm{Al}$ content and the inclusion density in the ingots $7 \mathrm{RP} 3,8 \mathrm{SN} 3$ and the electrode. It should however be remarked that the inclusions eliminated from the electrode are not only composed of aluminium and titanium compounds but also oxides of $\mathrm{Na}, \mathrm{Mg}, \mathrm{Zr}$ and $\mathrm{Ca}$. This is evidenced by the EPMA results shown in table 5. In view of this, it is difficult to quantify the variation in titanium and aluminium content in the ingot with inclusion density.

Three main mechanisms have been proposed (Peover 1972; Kay and Pomfret 1971; Mitchell 1974; Hawkins et al 1973) to explain the elimination of inclusions in ESR are: (i) Separation by flotation of inclusions in the liquid metal pool, ahead of solidifying interfaces in the ingot, 

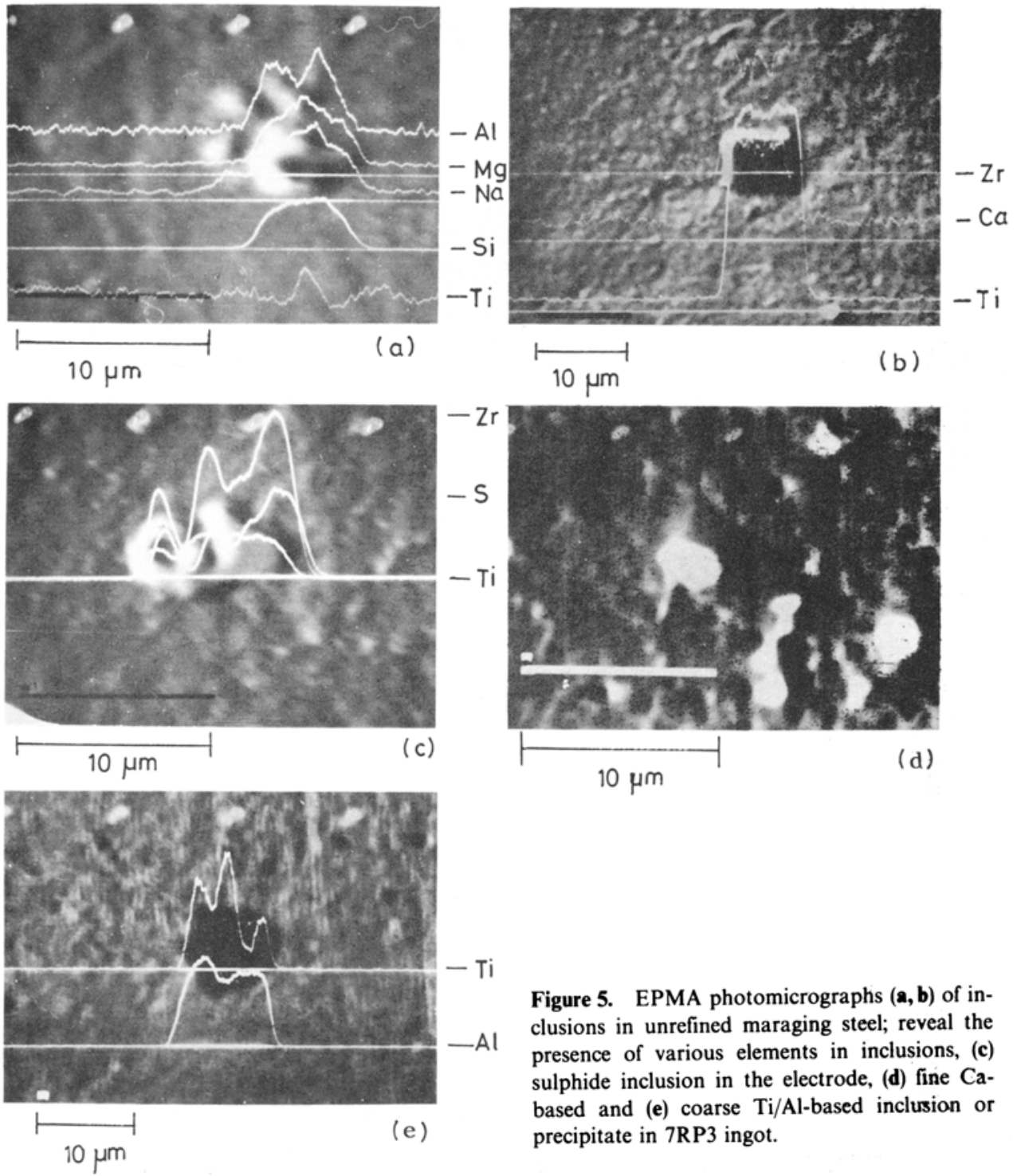

Figure 5. EPMA photomicrographs $(\mathbf{a}, \mathbf{b})$ of inclusions in unrefined maraging steel; reveal the presence of various elements in inclusions, (c) sulphide inclusion in the electrode, (d) fine $\mathrm{Ca}$ based and (e) coarse $\mathrm{Ti} / \mathrm{Al}$-based inclusion or precipitate in 7RP3 ingot.

Table 4. Density of inclusions larger than $2 \mu \mathrm{m}$ in size*

\begin{tabular}{lcc} 
Ingot No. & $\begin{array}{c}\text { Sample position } \\
\text { in the ingot }\end{array}$ & $\begin{array}{c}\text { Inclusions larger } \\
\text { than } 2 \mu \mathrm{m}\left(\mathrm{No}^{2} / \mathrm{mm}^{2}\right)\end{array}$ \\
\hline Electrode & Side & 55 \\
7RP3 & Centre & 4 \\
8SN3 & Side & 13 \\
& Centre & 47 \\
\hline
\end{tabular}

* corresponds to an average value of counts on fifteen fields of view. 
Table 5. Results of electron probe micro analysis of inclusions in maraging steel.

\begin{tabular}{|c|c|c|c|}
\hline Ingot No. & Nature of inclusion & Elements detected & Probable phase \\
\hline \multirow[t]{3}{*}{ Electrode } & Bright, irregular & $\mathrm{Al}, \mathrm{Mg}, \mathrm{Na}, \mathrm{Si}, \mathrm{Ti}$ & Oxide \\
\hline & Bright, irregular & $\mathrm{Zr}, \mathrm{Ti}, \mathrm{S}$ & Sulphide \\
\hline & Dark, square & $\mathrm{Zr}, \mathrm{Ca}, \mathrm{Ti}$ & Oxide \\
\hline \multirow[t]{4}{*}{ 7RP3 } & Dark, square & $\mathrm{Fe}, \mathrm{Ti}, \mathrm{Al}, \mathrm{Ni}$ & Oxide or precipitate \\
\hline & & & $\mathrm{Ni}_{3} \mathrm{Al}, \mathrm{Ti}_{3} \mathrm{Al}, \mathrm{Fe}_{3} \mathrm{Al}$ \\
\hline & White, irregular & $\mathrm{Ca}, \mathrm{Si}, \mathrm{Al}$ & Oxide \\
\hline & Dark, irregular & $\mathrm{Fe}, \mathrm{Ti}, \mathrm{Al}$ & Oxide or precipitate \\
\hline \multirow[t]{4}{*}{$8 \mathrm{SN} 3$} & Dark, irregular & $\mathrm{Fe}, \mathrm{Ti}, \mathrm{Al}, \mathrm{Ca}$ & Oxide \\
\hline & Dark, irregular & Fe. Ti, Ni, Al & Oxide or precipitate \\
\hline & Bright, square & $\mathrm{Fe}, \mathrm{Ti}$ & Oxide or carbonitride \\
\hline & Dark, large & $\mathrm{Fe}, \mathrm{Ti}, \mathrm{Ni}, \mathrm{Si}, \mathrm{Al}$ & Oxide \\
\hline
\end{tabular}

Table 6. Tensile properties of ESR-melted and non-ESR melted maraging steel.

\begin{tabular}{lccc}
\hline Ingot No. & $\begin{array}{c}0.2 \% \text { proof } \\
\text { strength } \\
(\mathrm{MPa})\end{array}$ & $\begin{array}{c}\text { Ultimate tensile } \\
\text { strength } \\
(\mathrm{MPa})\end{array}$ & $\begin{array}{c}\text { Percentage } \\
\text { elongation }\end{array}$ \\
\hline Electrode & 1302 & 1422 & $9 \cdot 6$ \\
7RP3 & 1320 & 1388 & 14.8 \\
8SN3 & 1017 & 1223 & $13 \cdot 3$ \\
\hline
\end{tabular}

Appropriately heat-treated to obtain the maximum hardness of $R_{c} 43$

Table 7. Fracture toughness $\left(K_{1 c}\right)$ of ESR-melted and non-ESR melted maraging steel.

\begin{tabular}{lcc}
\hline Ingot & $\begin{array}{c}\text { Direction of } \\
\text { sample in the ingot }\end{array}$ & $\begin{array}{c}K_{1 c} \\
(\mathrm{MPa} \sqrt{m})\end{array}$ \\
\hline Electrode & Transverse & 83 \\
7 RP3 & Transverse & 85 \\
8SN3 & Transverse & 68 \\
\hline
\end{tabular}

Specimens are appropriately heat-treated to attain maximum hardness of $R_{c} 43$

Table 8. Impact properties of ESR-melted and non-ESR melted maraging steel.

\begin{tabular}{lcccccc}
\hline Ingot No. & $\begin{array}{c}\text { Direction of } \\
\text { sample of } \\
\text { ingot }\end{array}$ & $\begin{array}{c}\sigma_{y d} \\
(\mathrm{MPa})\end{array}$ & $\begin{array}{c}K_{1 c} \\
(\mathrm{MPa} \sqrt{m})\end{array}$ & $\begin{array}{c}K_{1 d} \\
(\mathrm{MPa} \sqrt{m})\end{array}$ & $\begin{array}{c}\mathrm{CVN} \\
(\mathrm{Joules})\end{array}$ & DI $^{*}$ \\
\hline Electrode & Transverse & 1204 & 110 & 105 & 18.6 & $1 \cdot 13$ \\
$7 \mathrm{RP3}$ & Transverse & 1242 & 114 & 102 & 18.9 & 1.08 \\
$8 \mathrm{SN} 3$ & Transverse & 283 & 27 & 22 & 3.2 & 0.60 \\
\hline
\end{tabular}

(Specimens are appropriately heat-treated to obtain maximum hardness $R_{c} 43$ )

* Ductility index is the ratio of fracture propagation energy to the fracture initiation energy 

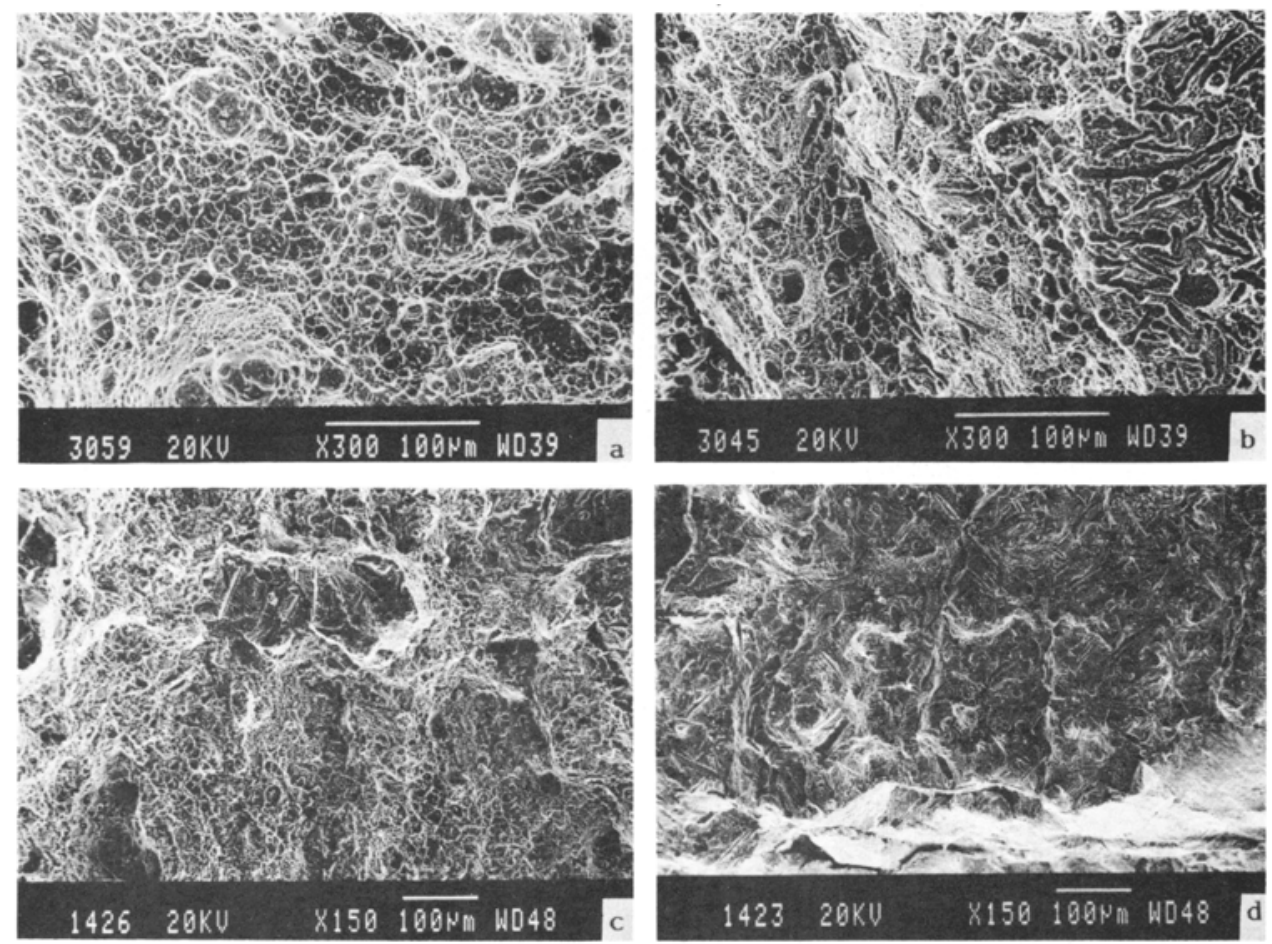

Figure 6. SEM photomicrographs of fractured maraging steel samples (heat-treated): (a) electrode, showing fine dimple fracture, (b) 7RP3: reveals fine dimple fracture, fracture of lath martensite is also visible, (c) ingot 7RP3: distribution of fine dimples can be seen and (d) ingot 8SN3: shows less of fine dimples.

(ii) elimination by adhesion of inclusions to the slag as a consequence of loss of surface energy when slag comes into contact with the metal, and

(iii) elimination by dissolution and dissociation of inclusions.

It is well known that a major portion of coarse and complex exogeneous inclusions present in the electrode is removed at the electrode site. The thickness of the molten film being very small $(20 \mu)$, the coarser inclusions which come into contact with molten slag are removed by adhesion to, and absorption by the slag as suggested by Hoyle (1983), and confirmed by Kay and Pomfret (1971). The present experimental results on the inclusion studies shown in tables 3 and 4 also lend support to this mechanism. Further, during formation and its travel through the slag, the metal droplet is subjected to intense internal mixing due to electromagnetic field and thermal agitation of the slag, thereby further aiding the elimination of inclusions via adhesion and absorption. It is evident from table 3 that the inclusion content is higher when melted with straight polarity than with the reverse. This can be attributed to the formation of a slag layer saturated with $\mathrm{FeO}$ at the slag/metal interface due to anodic polarization at the pool site when melting is carried out with straight polarity. The increase in concentration of the oxidizable elements in the metal pool which contribute to an increase in the inclusion content in the final ingot is governed by a 

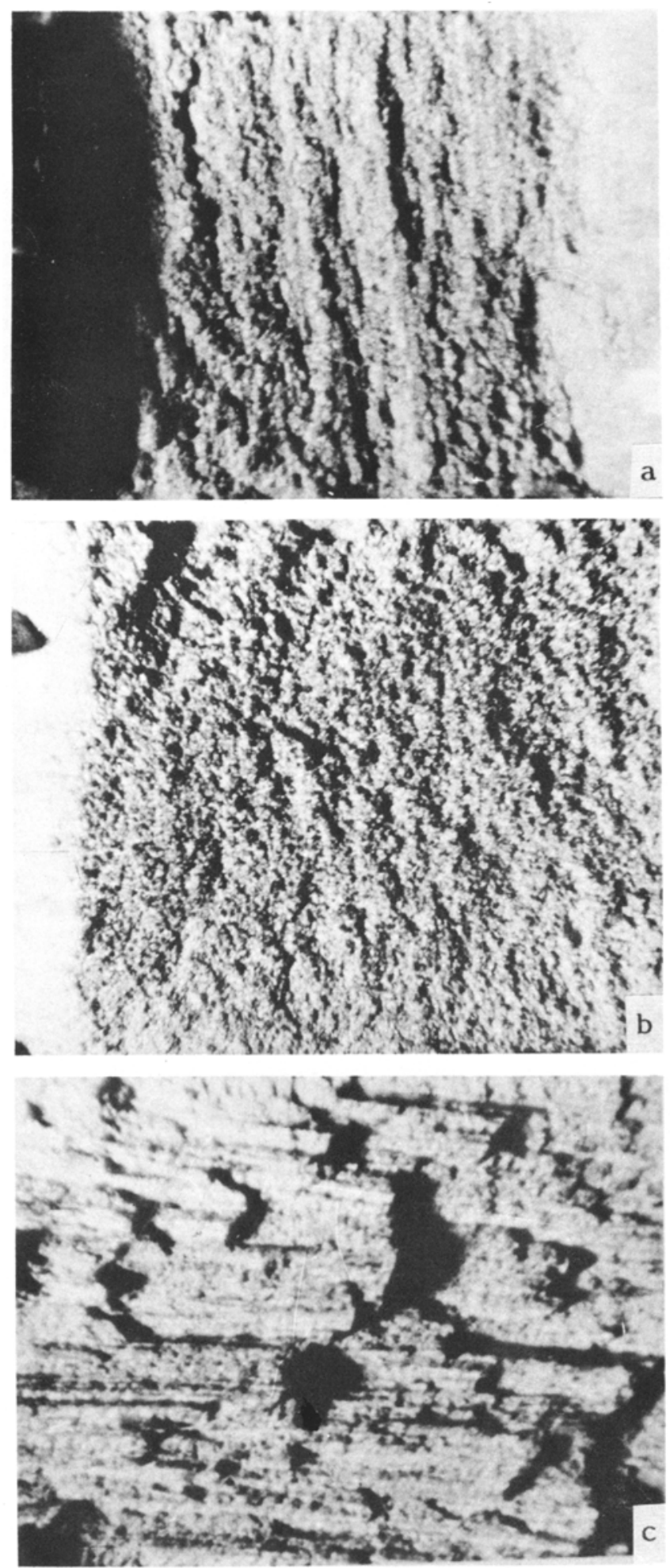

Figure 7. For caption, see p. 364. 
number of electrochemical reactions, notably the anodic reaction

$$
\left(0^{--}\right)-2 e=[0]
$$

at the metal pool.

Furthermore, elimination of inclusions can also occur by flotation from the metal pool. Removal of such inclusions which are not entrapped by the solidification front due to its poor wettability, is considered possible to a certain extent because sufficient time is available for inclusions greater than $2 \mu$ size to float to the slag-metal interface. It may be commented here that the process of dissociation and dissolution may not be a dominant mechanism for the removal of stable and high melting oxides like $\mathrm{Al}_{2} \mathrm{O}_{3}$ and $\mathrm{ZrO}_{2}$, as they require very high temperature for an appreciable degree of dissociation to occur. Mechanisms like flotation, adhesion and adsorption by slag may be responsible for their elimination. The influence of mode of solidification in ESR on inclusion content is noteworthy on two counts. First, elimination of inclusions from the molten pool by flotation is aided by the favourable solidification front in which dendrites are open to melt in contrast to the conventional casting in which inclusions are trapped by the dendrites in the converging columnar grains. Secondly, the mode of solidification plays a significant role in the distribution of inclusions in the ingot. At the side of the ingot, due to a high rate of solidification and a steep thermal gradient, the rate of nucleation is high, but the growth of inclusions is inhibited due to lack of time for material transport. At the centre of the ingot, due to lower rate of solidification, sufficient time is available for the growth of inclusions. Hence the side of the ingot is cleaner and inclusions are finer in comparison to the centre of the ingot as evidenced by the results given in tables 3 and 4 .

With regard to the mechanical behaviour, ingot 7RP3 which is ESR-melted in DC reverse polarity, in spite of loss of $\mathrm{Ti}$, has registered mechanical properties matching those of thermo-mechanically treated maraging steel produced by non-ESR route (both being given the equivalent heat treatment) as can be noted from table 6. It is clear from the results that, not withstanding the loss of aluminium and titanium, ESR-melted maraging steels possess good mechanical properties, even without being subjected to thermomechanical treatment. This work thus affirms that the ESR process can be suitably adopted for electroslag casting and/or electroslag welding of maraging steels, where improvement in properties by thermomechanical treatment is either difficult or impossible. Cast structure is known to be inferior to wrought structure due to inherent microsegregation in the former, which cannot be totally eliminated by homogenization even when annealed at high temperatures for long durations. Thermomechanical treatment is generally needed to homogenize the sample by breaking down the dendritic structure. The major reason for the superior mechanical properties exhibited by electroslag cast maraging steel is the effective removal of inclusions, in particular the coarser ones. Void nucleation in the case of maraging steels generally occurs by the fracture of coarser inclusions (Cox and Low 1974). In the absence of coarse inclusions, void nucleation occurs around finer inclusions and/or precipitates at higher stress levels and this leads to superior mechanical properties and to a fine and uniform dimple fracture appearance as revealed in figure 6. Apart from the higher proportion of coarser inclusions, the reason for inferior properties exhibited by the ingot $8 \mathrm{SN} 3$ is the grain boundary precipitation as revealed by the photomicrograph in figure 2. A similar phenomenon is not observed in ingot 7RP3. 
Cox and Low (1974) have compared the fracture process in En 24 and maraging steels. They found that voids were nucleated by fracture of $\mathrm{Ti}(\mathrm{C}, \mathrm{N})$ inclusions in maraging steel as against by decohesion around $\mathrm{MnS}$ inclusions in the case of En 24. However, the critical difference between the two steels is found in void growth and coalescence stage. In maraging steels, these voids grow until impingement causes coalescence and final failure. As opposed to this, the growth of initial large voids in En 24 is terminated prematurely by the development of void sheet, consisting of small voids linked to large voids. Cox and Low (1974) concluded that the superior toughness exhibited by maraging steel could be attributed to their much lower tendency to form void sheets in presence of fine precipitates. Roesch and Henry (1969) have observed dimples in the regions surrounding inclusions and precipitate in maraging steels. However, only a fraction of the particles (inclusions or precipitates) participate in the fracture process. There exists a critical size for particles $(\sim 200 \AA)$ below which dimples do not nucleate and fracture process is delayed in these regions. Finely distributed precipitates, in the absence of inclusions, therefore improve the fracture toughness of maraging steels, although table 7 shows nearly equal $K_{1 c}$ values for the electrode $(83 \mathrm{MPa} \sqrt{m})$ and the ingot $7 \mathrm{RP} 3$. It must be noted that the electrode material is already subjected to thermomechanical treatment whereas the ESR sample is not. The ESR process has thus extensively contributed to improved fracture toughness by lowering the inclusion content. The results of impact properties obtained on maraging steel as presented in table 8 indicate that the ductility index for ingot $7 R P 3$ is greater than unity, suggesting that the energy required for propagation is more than that required for crack initiation. This is to be expected because in the absence of inclusions, void sheet has to overcome the resistance of ligament between the voids for crack propagation. By contrast, in the case of ingot $8 \mathrm{SN} 3$, coarse inclusions present undergo fracture and provide an easy path for crack propagations as supported by its low ductility index. The foregoing discussion has clearly shown that ESR-melted maraging steel exhibits mechanical properties which are as good as those of thermo-mechanically-treated maraging steels produced by the non-ESR route.

\section{Conclusions}

The present study confirms that the metallurgical characteristics of MDN-250 maraging steel can be significantly improved by electroslag refining. The ingots produced by the reverse polarity mode of melting were found to possess consistent chemistry, low inclusion rating and better mechanical properties than those produced by the straight polarity mode and non-ESR route.

\section{Acknowledgements}

The authors are grateful to the Aeronautical Research and Development Board for sponsoring the project. One of the authors (KRU) is indebted to the Principal, Karnataka Regional Engineering College, Srinivasnagar, Surathkal for sponsorship under the Quality Improvement Programme to execute the work. 


\section{References}

Bannerjee B R and Hauser J J 1977 in Proc. Symp. on Transformation and Hardenability of Steels (Climax Molybdenum Corporationj p. 13

Cox T B and Low J R 1974 Metall. Trans. 51457

Fontaine P I and Palmer D J 1972 J. Iron Steel Inst. 210286

Hawkins R J, Swinden D J and Pocklington D N 1973 in Electroslag Refining (London: The Iron and Steel Institute) p. 21

Hertzberg R W 1978 in Deformation and Fracture of Engineering Materials (New York: John Wiley) p. 363

Holzgruber W, Machner P, Pocklinger E and Boehler G 1969 Trans. Vac. Met. Conf. (New York: Am. Vac. Soc.) p. 415

Hoyle G 1983 in Electroslag Process-Principles and Practices (London: Applied Science) p. 168 (First Edition 1969)

Ireland D R 1973 ASTM STP 5634

Kay D A R and Pomfret R J 1971 J. Iron Steel Inst. 201962

Krasnikov S I and Kuzmenko S I 1982 Steel in USSR 1263

Latash Yu and Medovar B I 1972 in Electrometallurgy (Naukova Dumka: Kiev) p. 100

Mitchell A 1974 Iron Making Steel Making 3172

Peover M E 1972 J. Inst. Metals 10097

Perkas M P 1985 Metallo. Termi. Obra. Mellaov 523

Robinson N and Graninger J A 1963 Metallurgia 67 1616

Roesch R and Henry G 1969 ASTM STP 455103

Figure 7. Stereophotographs $(\times 25)$ of surfaces of maraging steel samples fractured under impact loading: (a) unrefined electrode: directionality in fractured lines visible. (b) ingot 7R P3, heat-treated: reveals uniform fine-fractured grains, $(c)$ ingot $8 \mathrm{SN} 3$, heat-treated: coarse and brittle-fractured grains visible. 